\title{
Some Measures to Train Critical Thinking Capacity for Pedagogical Students in Vietnam Nowadays
}

\author{
Nguyen Thi Nga \\ Faculty of Politic Theories and Civic Education \\ Hanoi National University of Education, Hanoi, Vietnam
}

\begin{abstract}
The development of critical thinking and critical capacity for pedagogical students in Vietnam is an urgent requirement. The capacity of critical thinking helps students have a positive outlook, easily recognize and remove old and outdated ones, actively approach new things, progress in thinking and action. The article clarifies the characteristics of critical thinking capacity of pedagogical students in Vietnam, thereby proposing some measures to train students' critical human resources.
\end{abstract}

Keywords: capacity, critical thinking, pedagogical students, Vietnam, measure

DOI: $10.7176 /$ RHSS/10-18-07

Publication date:September $30^{\text {th }} 2020$

\section{Introduction}

Critical thinking is the necessary thinking capacity that plays an important role in the learning and research process of students at university. The training of critical thinking capacity helps students to have a multi-dimensional view, recognize and evaluate problems based on convincing grounds and arguments, to be confident to practice your job in the future.

Recognizing the importance of training critical thinking capacity for students, pedagogical universities in Vietnam have made many efforts, changed their perception as well as achieved certain achievements. However, due to the influence of Asian thinking and the long tradition of education in Vietnam, the training of critical thinking capacity for pedagogical students has alot of limitations such as: the awareness and the critical thinking capacity of students, lecturers and administrators are still inadequate; Content, teaching methods are imposed, oneway, not promoting the potential, feedback or creativity of students, ... These limitations pose problems that need to be thoroughly resolved in order to improve the efficiency of training critical thinking capacity for pedagogical students in Vietnam today.

\section{Main content}

\subsection{Critical thinking capacity}

The concept of critical thinking

The term "Critical Thinking" is derived from the two ancient Greek language: "kriticos" (meaning Judicious judgment) and "kriterion" (meaning standard). Etymologically, this word implies the development of "judicious judgment based on standards".

Taken from Richard Paul và Linda Elder: "Critical thinking is that mode of thinking - about any subject, content, or problem - in which the thinker improves the quality of his or her thinking by skillfully taking charge of the structures inherent in thinking and imposing intellectual standards upon them" [11].

The concept of capacity

Capacity is all qualities, abilities, and characteristics of a person (psychological and physiological) that ensures the performance of a certain activity.

In the conception of UNESCO: capacity includes knowledge, skills and attitudes; The last two factors belong to life skills, which play a decisive role in forming a person's personality, character, and professionalism.

The concept of critical thinking capacity

Critical thinking capacity is the synthesis of qualities and ability to think in knowledge transformation, experience and capacity to reason in detecting, considering and evaluating problem situations, and proving scientific or antiscientific hypotheses, forming new knowledge.

Factors that constitute critical thinking capacity

The fist factor is the capacity to receive information in rational thinking. Any thinking process must start from collecting and receiving information. When receiving information, it is important to have a clear understanding of that information, carefully know the necessary information, important, related to any problem, any field, ... Especially in the period of information technology development today, information is given from many different sources and maybe has fake news. Therefore, knowing to receive information accurately, quickly and appropriately is a necessary thinking capacity.

The second factor is the information processing capacity with grounds and arguments. After receiving information, the problem is how to handle that information properly and appropriately. The processing of factual 
and argumentative information must be based on scientific and logical grounds. This information processing is done through the manipulation of logical thinking. Through the construction of the manipulations of thought such as concept, judgment, inference, from the initial received information, thought will determine the necessary and correct information by responding to the questions like: why that conclusion is correct for this things but not for others. And from this information will lead to certain conclusions, not other conclusions, ...

The third factor is the ability to evaluate as well as to refute the results of other thinking processes to redefine the accuracy of the information received by the perceived subject. Through the manipulations of logical thinking, the cognitive subject has made certain conclusions about things. However, for that conclusion to become the truth, it is necessary to have a comparison with the conclusions of other thinking processes. Here, critical thinking requires cognitive subjects to both have the capacity to judge and to argue against the results of other thinking processes. That means the subject must be able to perceive the results of other thinking processes in order to judge whether the conclusion is true or false, and if false, can be challenged. This rebuttal does not mean rejecting, completely negating the views of others, just admitting personal views. If the results of other thinking processes are correct, this capacity also requires the cognitive subject to know how to absorb and admit.

The fourth factor is the ability to detect new problems in the process of receiving, processing and determining the accuracy of information. The critical thinking process is the foundation of creative thinking. In the process of receiving, processing and determining the accuracy of information, cognitive subjects need to detect new problems arising from researching problems. These new problems show the creativity of the subject's cognitive process.

\subsection{Critical thinking capacity characteristics of pedagogical students in Vietnam nowadays}

In Vietnam, there are 154 teacher training institutions, including 15 pedagogical universities, 48 multi-disciplinary universities with teacher training, 30 pedagogical colleges, 19 multi-disciplinary colleges with teacher training, 02 intermediate schools for pedagogy and 40 multi-disciplinary middle schools are training preschool teachers [2].

Currently, the model and method of teacher training in pedagogical universities in Vietnam is very diverse. It can be generalized into 3 modes: The first is training teachers at universities according to the traditional method: training basic faculties (majors) and pedagogical training (parallel model) is done current 4 years. The second is teacher training in 2 phases (serial model): training in basic science / specialization then training pedagogical profession. The third is inter-training (from intermediate education, pedagogical college to pedagogical university), often in the form of learning by doing.

Pedagogical students are young people who have good health, smart qualities, dreams and ambitions for a good future. These students have passed the challenge, were tested for their competency and intelligence through the national entrance exam. They are in the active process of self-training, learning, improving their professional skills, pedagogical skills and fostering the qualities and pedagogical competencies needed to meet the requirements of the career in the future. These are people with good health, intelligence, energy, quality, dreams, ideals and willingness to contribute. However, at this age, because of the enthusiasm of youth as well as the desire to assert themselves, students can easily make impatient and immature decisions.

Unlike students in other disciplines, pedagogical students must actively practice and foster specific competencies and qualities of their careers such as teaching capacity, student understanding, and communication skills, the ability to handle pedagogical situations, the ability to speak fluently and proficiently. In particular, they must regularly train and foster the necessary logical thinking capacities such as dialectical thinking capacity, critical thinking capacity, creative thinking capacity, ... This thinking helps pedagogical students know how to think, analyze, evaluate, and solve problems that arise in the learning and research process. At the same time, regular practice and self-training will help pedagogical students have good logical thinking ability, well perform the duties of the teacher in the future.

To assess the status of critical thinking capacity of pedagogical students in Vietnam today, the author has conducted a thinking test on 1850 students from 5 pedagogical universities across the country. The test consists of 5 questions with a series of specific situations expressed in words or data to test the ability to grasp information, check the logic of information and the ability to manipulate of thinking like analyzing and evaluating to detect logical errors, inaccurate and incomplete arguments in the answers. From there, students can correctly understand conclusions and deduce confounding information (information in approximate or misleading answers). Each correct answer will be awarded 1 point. The number of points corresponding to the student's critical thinking ability is calculated as follows:

5 points: Students have very good critical thinking capacity, skills to analyze, evaluate and process information quickly.

4 points: Students have good critical thinking capacity but still get confused with complicate information.

3 points: Students have critical thinking capacity, however, it is necessary to practice skills of receiving and analyzing to accurately assess information and make right decisions.

1 or 2 points: the skills of processing and analyzing, assessing information are not good, and also being deceived in tricky situations and misleading information. 


\begin{tabular}{|l|l|l|}
\hline \multicolumn{3}{|l|}{ The results of the critical thinking test } \\
\hline Score & Quantity & Percentage \\
\hline Reach 4-5 & 498 & $26,9 \%$ \\
\hline Reach 3 & 997 & $53,9 \%$ \\
\hline Less than 3 & 355 & $19,2 \%$ \\
\hline Total & 1850 & $100 \%$ \\
\hline
\end{tabular}

Inside:

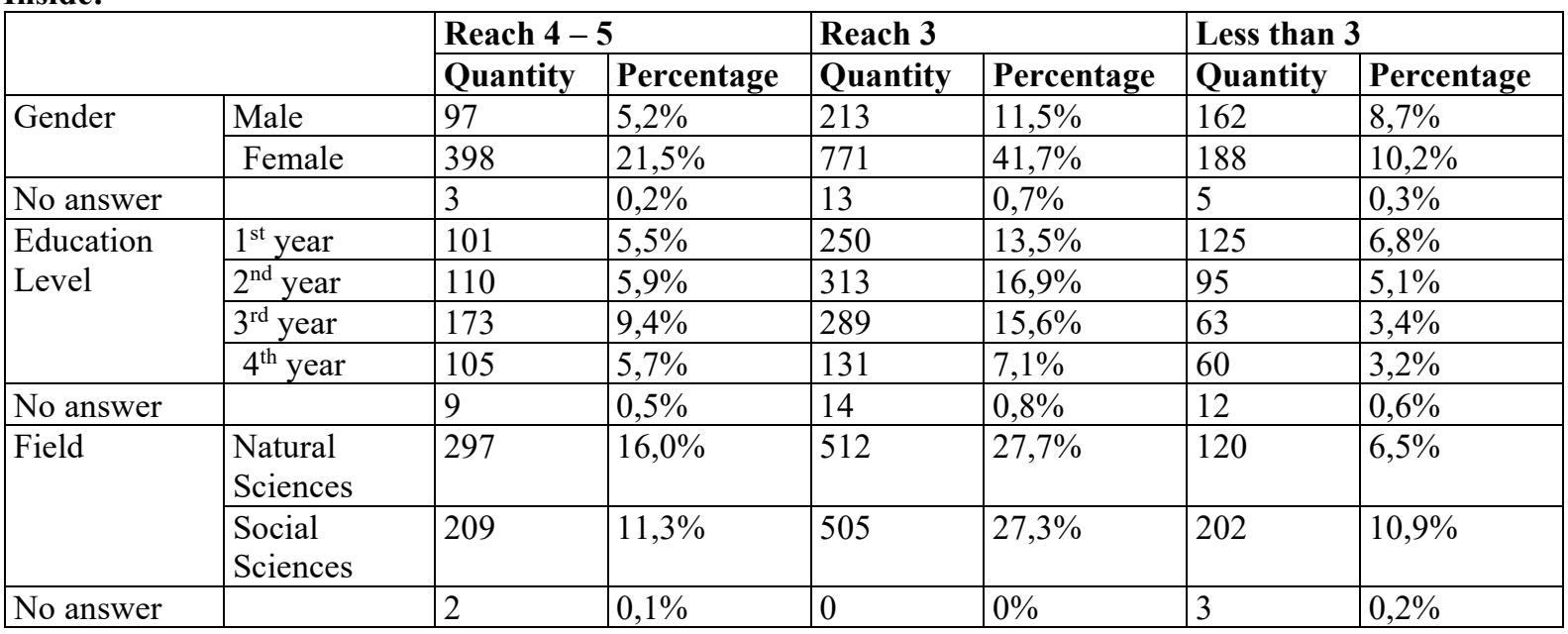

The survey results show that the majority of students initially have the critical thinking capacity, basic skills such as receiving and processing information are quite good: 498 students scored 4, 5 (accounting for 26.9\%); 997 students scored 3 (accounting for 53.9\%). Pedagogical students began to know how to use the basic manipulations of thinking to analyze and evaluate received information, from which to make quick and accurate decisions. These students are often highly independent, self-conscious, serious and passionate about learning and research. They are also people who are not easily content with everything they learn from teachers or books, but always have to explore and research to expand their own knowledge. They often turn problems, posing scientific "doubts" about the situations that occur in study, research, and life. These students often identify, analyze very quickly and accurately the received information to evaluate and make conclusions, scientific problem solving methods. Therefore, students with this capacity of critical thinking often achieve high results in study and research, and at the same time, they are also very successful in life. Because, before each problem arises, students with the capacity of critical thinking often consider to see the basis of the way, find the good, the weak point, the unreasonable in the solution. Therefore, the conclusions they make are often accurate, thoroughly solving the arising problems. In addition, students with critical thinking ability can evaluate and improve creative ideas because they always have a positive outlook, towards new things. It can be said that critical thinking is the foundation to develop students' creative thinking.

However, the proportion of pedagogical students with poor critical thinking capacity still accounts for a high proportion $(19.2 \%)$. These students still have many limitations in receiving and processing information. They also have many difficulties in analyzing and evaluating information, leading to deception and inaccurate conclusions [6]. These students are often shy or not active when participating in teamwork, with low independent thinking ability and low self-awareness. They are used to relying on teachers and have no habit of thinking. They are also afraid or have a psychology of fear of losing their teachers and friends when giving opposing opinions or simply not daring to express their own opinions. Therefore, the critical thinking skills of these students are also very limited, their passivity and dependence are high. That also leads to a sense of fear and one-way thinking, looking at the problem in an unrequited and negative way. This has a significant impact on their learning, research and work in the future.

Reality in the process of training and fostering pedagogical skills and the results of the internship process has shown the ability to communicate, behave, process information and the ability to adapt to professional training activities of pedagogical students still have many shortcomings. Even in the month or week of training in pedagogy at the school, many students have an indifferent attitude, considering it a week of relaxation, not having to study culture or seeing it as a competition activity of the participants, not related to them; Many activities in the professional week at pedagogical universities are still formal or competitive among classes, departments, so only focus on a part of students taking the exam without paying attention a large number of students. Therefore, when students go to high schools to practice, the internship is weak and lacks in basic pedagogical skills, especially in handling pedagogical situations.

In addition, pedagogical students also have difficulty in resolving conflicts between theories and information 
received from universities and the requirements and reality of teaching at schools. The study in pedagogical universities today still focuses on theory, the practical modules still account for a small proportion; Seminar activities, team work, presentations, rhetoric, .. are very limited in time, content and form of expression. Therefore, pedagogical students are often very greedy about knowledge, have not identified the key knowledge leading to lectures spread out, have no highlights and often "lesson plans" burned. This is a very common practice in the internship process of pedagogical students.

The capacity of rebuttal and rhetoric of pedagogical students is limited. Students do not dare to speak contradictory opinions of the majority, not brave enough to raise and defend their own opinions to the end.

\subsection{Some measures to train critical thinking capacity for pedagogical students in Vietnam nowadays}

Firstly, lecturers must classify and evaluate students' cognitive level in order to choose suitable teaching methods. The awareness level of pedagogical students is not equal due to the large difference in input quality among disciplines and faculties in the university; disparities between the natural sciences and the social sciences. Students studying groups of natural sciences (such as math, physics, chemistry,...) often have the capacity thinking clearly and independently, prefer to work individually instead of participating in team work. These students have relatively good ability to work independently with the document, analyze and synthesize the resources. Therefore, the products of their activities are often presented in a relatively clear way, demonstrating a coherent, logical way of thinking. However, that was quite different from students studying social sciences groups. Because, these students often have strengths in teamwork, they are relatively sociable, show their enthusiasm to participate in joint activities. They like to do projects related to creativity and art, which is most evident in deciding the electives. Therefore, for them, the implementation of the manipulation of logical thinking or especially the training of critical thinking skills will face more difficulties. Thus, students in each of the natural or social sciences have their own advantages and disadvantages when forming and developing the capacity of critical thinking. Moreover, the development of critical thinking capacity depends on cognitive level, thinking capacity, innate factors and selfawareness and responsibility of each student. It can be said that, at each different level of perception, pedagogical students have different perspectives and critical thinking abilities. Therefore, the teacher must have an overview of the student's thinking capacity and cognitive level to change, apply appropriate teaching methods to form and train the critical thinking capacity for them [8].

Secondly, lecturers train critical thingking capacity for pedagogycal students through deliberation, discussion and deliberate exercises. The critical thinking capacity of pedagogical students will be conducive to developing and exercising in a happy, comfortable, open, and critical classroom atmosphere. To do that, the role of the lecturers is very important. Because when the lecturer is the initiator, enthusiastic participation in the issues creates a strong attraction for students to the topic being discussed. At the same time, they should also create an open, happy classroom atmosphere, giving students the opportunity to express and defend their own opinions and opinions. In order for students to actively and effectively participate in the debate and discussion process, it requires lecturers to know how to ask questions as well as assign tasks appropriately for students. With these questions, students can come up with many different solutions, but must base themselves on different approaches and use arguments to prove convincing. During discussion, lecturers need to respect, listen to students' opinions, assist students in examining their basis of thinking. Lecturers should encourage students to actively participate in debates, respect the opinions of others during debates; not blindly accept others' opinions and be open to different points of view; know how to care about other people's opinions and accept strange ideas, contrary to your own if it is based on the exact scientific basis. For shy students, teachers need encouragement to be more active in discussions and class periods. Through the lessons, discussions, and debates will help pedagogical students to form and practice critical thinking skills effectively. However, to a certain extent, lecturers must still guide students to find out scientific knowledge after those discussions and exchanges, allowing them to memorize and supplement knowledge.

Thirdly, lecturers practice students the habit of critical thinking. Teaching critical thinking for pedagogical students is necessary, but more importantly, it is necessary to make them realize and practice it as a habit in learning and life, turning it into their own skills. Lecturers should encourage students to be skeptical of science, to distinguish scientific skepticism from all doubts, not to believe in anything, to not believe in anyone. In the face of certain information, students need to doubt the authenticity of the information, should not rush to conclude that information is right or wrong, but must rely on scientific grounds to make analysis accurate reviews and conclusions about information [3]. Instructors guide students to ask questions before a problem posed, orient them to ask the question in the right focus, at the right time, at the right place. This practice of scientific skepticism helps students to carefully consider all issues, relevant information, check their assumptions before coming to conclusions or make decisions, ensuring that conclusions are drawn logical way from hypothesis, with scientific basis. The instructor should instruct students to dismiss false, erroneous or ambiguous assumptions; require students to make sure that they do not violate the logic of rules, identify the types of fallacies, ensure certain facts about the facts, and grasp the concepts firmly; explain the reasons, prove their point of view; Use correct language 
to confirm your conclusions, avoid making claims that cannot be proved. Therefore, students will avoid mistakes and shortcomings when making decisions and conclusions about the accuracy of information. To train the habit of critical thinking for pedagogical students, lectures can ask students to make different assumptions and plans to solve the same problems that arise in their learning and training process. That will encourages students to think independently and come up with different options to solve the problem, consider both the right and the reverse side of a problem, and analyze the positives and limitations of each project, from which decide to choose the most optimal option.

\section{Conclusion}

Critical thinking is an important capacity that any pedagogical student needs to form, foster and regularly practice to apply flexibly, creatively in learning, research and career in the future. In particular, in the current trend of globalization and international integration, training people with comprehensive development, capable of critical thinking, capable of meeting the increasing demands of society, moving towards forming a global citizen is an urgent requirement of Vietnam's education. Therefore, in addition to the formation and fostering ethical qualities of teachers, pedagogical competencies, and professional qualifications, the training of critical thinking capacity for pedagogical students has important implications to perfect their personality, have a positive outlook and confidence in practice and in life.

\section{References}

1. Tran Thi Tuyet Anh (2009), Forming critical thinking for students in the teaching process in university, Journal of Education (213).

2. Ministry of Education and Training (2011), Program for the development of Pedagogy and Pedagogical Schools from 2011 to 2020, No. 6290 / QD-BGDĐT.

3. Ta Khac Dinh (2007), Train students' independent thinking ability to explore, discover and solve problems, Today's Teaching and Learning Magazine, No. 3.

4. Nguyen Van Do (2017), Critical thinking in language education, Journal of Language and Life, No. 12.

5. Nguyen Ngoc Ha (editor) (2011), Thinking characteristics and lifestyle of Vietnamese people today: Some theoretical and practical issues, Social Science Publishing House, Hanoi.

6. Le Thi Thu Ha (2014), Factors affecting decision-making skills of students, Journal of Education (336).

7. Do Khanh Nam (2014), The process of training negotiation skills for students ", Journal of Education, (331).

8. Bui Ngoc Quan (2016), Activate teaching activities of lecturers in training critical thinking for students, Journal of Education (377)

9. Donald J. Treffinger (2009), Preparing creative and critical thinkers, ADSL, USA.

10. Kurfis (2001), Critical thinking, Self directed learning resource, Learning Resource Center and Learning Development, University of Wollongong, PDF format.

11. Richard Paul and Linda Elder (2008), The Miniature Guide to Critical Thinking Concepts and Tools, Foundation for Critical Thinking Press. 